\title{
MAPEAMENTO SOBRE O TEMPO E SUAS INFLUÊNCIAS NAS AULAS de EdUCAÇÃo Física ESCOLAR NOS PERIÓdicos BRASILEIROS (2000-2019)
}

\author{
MAPPING ABOUT TIME AND ITS INFLUENCES IN SCHOOL PHYSICAL \\ EDUCATION CLASSES IN BRAZILIAN JOURNALS (2000-2019)
}

DOI: 10.23926/RPD.2526-2149.2020.v5.n3.p1646-1665.id851

\section{João Victor de Mello Avelino \\ Mestrando em Educação \\ (UFPR) \\ jv.avelino1510@gmail.com}

\section{Letícia Cristina Lima Moraes}

Mestranda em Educação

Física (UFPR)

letsmoraes96@gmail.com

\section{Letícia Godoy}

Doutora em Educação Física (UFPR)

godoyleticia@bol.com.br

\section{Cristina Carta}

\section{Cardoso de Medeiros}

Doutora em Educação (UFPR)

cricaccm@gmail.com
Resumo: As pesquisas sobre a organização do tempo nas aulas de Educação Física escolar parecem incipientes. O presente estudo teve como objetivo geral identificar como a produção científica na área da Educação Física tem tratado o tema sobre gerenciamento do tempo e seus desdobramentos nas estratégias metodológicas e didáticas nas aulas de Educação Física escolar. Trata-se de um estudo de revisão de abordagem qualitativa. Para a composição do escopo de pesquisa foram utilizados periódicos nacionais pré-estabelecidos, sendo recorte temporal do ano 2000 até 07/2019. Foram encontrados 55 artigos relacionados ao tempo e às suas influências. Os eixos prática pedagógica e motivação foram os que tiveram a maior concentração de estudos, enquanto os eixos competência e tempo apresentaram uma certa incipiência. O estudo contribui de modo a apresentar os tópicos menos explorados, apontando caminhos escassos passíveis de maior investimento do setor científico.

Palavras-chave: Educação Física Escolar. Tempo. Revisão.

\begin{abstract}
Research on the organisation of time in school physical education classes seems incipient. The general objective of the present study was to identify how scientific production in the area of Physical Education has dealt with the topic of time management and its developments in methodological and didactic strategies in school Physical Education classes. It is a review study of qualitative approach. For the composition of the research scope, pre-established national periodicals were used, being a time cut from 2000 to 07/2019. 55 articles related to time and its influences were found. The practical pedagogical and motivational axes were the ones with the highest concentration of studies, while the competence and time axes presented a certain incipiency. The study contributes in order to present the less explored topics, pointing out scarce paths that can be more invested in the scientific sector.
\end{abstract}

Keywords: School Physical Education. Time. Review. 


\section{INTRODUÇÃ̃ ${ }^{1}$}

O tempo dispendido com questões administrativas nas aulas de Educação Física, como a formação de filas, idas a bebedouros, momentos de advertências, saída e volta para a sala, banheiros, isto é, elementos componentes da cultura da escolar ${ }^{2}$, considerados muitas vezes como parte constitutiva da rotina e enraizada na prática dos professores, delimita ainda mais o tempo da própria aula, que precisa dar conta de controlar a turma, explicar e contextualizar o conteúdo planejado, organizar espaços e materiais, entre outras variáveis. Ainda, corroborando negativamente, a grade curricular escolar garante uma carga horária diminuta ${ }^{3}$ para a Educação Física, contribuindo com um possível déficit na formação dos alunos em relação a essa área do conhecimento.

Todos esses fatores que cerceiam o ambiente escolar remetem às questões específicas da aprendizagem ativa, da organização e administração do tempo nas aulas de Educação Física escolar. Esses assuntos são relevantes para se discutir na área, porém as pesquisas publicadas sobre esses tópicos ainda parecem escassas no campo (COUTINHO et al. 2012; BRACHT et al. 2011), demonstrando, dessa forma, a não apreensão específica, por parte do meio científico, em relação a esses aspectos que compõem o cotidiano da aula de Educação Física na escola.

Tendo em vista esse cenário árido da produção científica em relação a essas abordagens, a questão norteadora para o presente estudo foi: de que forma a produção científica na área da Educação Física tem tratado o tema gerenciamento do tempo e seus desdobramentos nas estratégias metodológicas e didáticas nas aulas de Educação Física escolar? O objetivo geral, nessa perspectiva, foi identificar como a produção científica na área da Educação Física tem tratado o tema gerenciamento do tempo e seus desdobramentos nas estratégias metodológicas e didáticas nas aulas de Educação Física escolar. De modo específico, procurou-se: a) mapear e descrever a composição dos estudos publicados em periódicos nacionais da área da Educação Física sobre o tema gerenciamento do tempo e seus desdobramentos nas estratégias metodológicas e didáticas nas aulas de Educação Física escolar; b) identificar o perfil temático

\footnotetext{
${ }^{1} \mathrm{O}$ presente trabalho não contou com apoio financeiro de nenhuma natureza para sua realização. Deriva do trabalho de conclusão de curso intitulado "Estado do conhecimento em periódicos brasileiros sobre o gerenciamento do tempo e suas influências nas aulas de Educação Física escolar", apresentado na Universidade Federal do Paraná em 2019.

2 "Cultura da escola" é um termo utilizado por Forquin (1993) para caracterizar a escola como um mundo social, que tem suas características de vida próprias, seus ritmos e seus ritos, sua linguagem, seu imaginário, seus modos próprios de regulação e de transgressão, seu regime próprio de produção e de gestão de símbolos.

${ }^{3}$ A antiga Lei n. 5.692 de 1971 estabelecia a aula de Educação Física com a hora-aula de 50 minutos, no entanto esse fator ficou a cargo de cada sistema de ensino conforme a Lei n. 9.394 de 20 de dezembro de 1996, atual LDB. Por esse motivo, o tempo médio de cada aula de Educação Física vária entre as escolas, mas ainda continua sendo duas aulas semanais de 50 minutos cada na maioria das instituições.
} 
das produções sobre gerenciamento do tempo e suas influências; c) apontar quais são as instituições e os grupos de pesquisa que se ocupam dessas discussões.

Esse estudo se justifica à medida que os resultados obtidos pelo levantamento e mapeamento da produção que trata sobre o gerenciamento do tempo e suas influencias nas estratégias metodológicas e didáticas nas aulas de Educação Física escolar poderão ser utilizados nas áreas da Educação e Educação Física, para estimular a ampliação de novos estudos e, principalmente, no que se refere à apropriação desses dados pelos profissionais da área. Esse movimento poderá fazer com que os professores utilizem este material como referencial no aprimoramento do seu fazer pedagógico.

Entende-se, ainda, que a coleta dos dados e as análises que foram realizadas auxiliarão na identificação de como os estudos sobre a prática pedagógica e o uso do tempo na Educação Física têm se desenvolvido nas revistas da disciplina, bem como quais os tipos de abordagem esse tema tem tido e representados em forma de artigos nos periódicos. A escolha da utilização desse tipo de suporte empírico se deve a uma tentativa de se afastar de discursos já estabelecidos acerca do estado do campo (MALCOLM, 2012), amparando-se em dados mais objetivos para realizar essa avaliação, sem a intenção, no entanto, de comparar os conteúdos de cada revista visto que cada uma apresenta singularidades.

A seguir, será realizada a apresentação teórico-metodológica na qual se embasou a pesquisa, evidenciando os pressupostos e as buscas feitas para compor a pesquisa de revisão, bem como o detalhamento organizacional e a criação dos eixos temáticos da pesquisa. Depois dessa etapa, inicia-se a exposição dos resultados por meio de representação gráfica, acompanhada das discussões dos mesmos. Por fim, nas considerações finais, são retomados os objetivos do estudo, destacando os principais resultados encontrados, as limitações do estudo e os possíveis caminhos para novas pesquisas.

\section{Metodologia}

Esta pesquisa se encaixa em um conjunto de trabalhos que se consolida como "estado do conhecimento". De acordo com Morosini e Fernandes (2014), esse tipo de estudo busca a identificação, o registro e a categorização que levem à reflexão e à síntese sobre a produção científica de uma determinada área/tema, em um determinado espaço de tempo. Esse tipo de trabalho contribui para a construção de uma memória da educação, uma vez que produz um banco de dados sobre as produções por meio do mapeamento e da discussão das pesquisas acadêmicas (FERREIRA, 2002). 
Partindo dessa premissa, para a composição do escopo da pesquisa de mapeamento, foram utilizados artigos publicados em português nos periódicos nacionais com foco em Educação Física escolar, em um intervalo de classificação entre A1 e B5, segundo a classificação de periódicos (Qualis) ${ }^{4}$ no quadriênio de 2013-2016 pela Coordenação de Aperfeiçoamento de Pessoal de Nível Superior (CAPES). Os periódicos foram selecionados com base, primeiramente, na busca por revistas de Educação Física nas bases de dados que declarassem claramente em seu foco e escopo a ligação com a vertente pedagógica. Além disso, foi realizada uma visualização prévia dos conteúdos dos periódicos para identificar se haveria produções sobre as temáticas e se essas revistas se enquadravam no intervalo de classificação.

Ao fim, os periódicos selecionados foram: Movimento (A2), Journal of Physical Education (B1), Motriz (B1), Revista Brasileira de Educação Física e Esporte (B1), Revista Brasileira de Ciências do Esporte (B1), Motrivivência (B2), Pensar a Prática (B2) e Mackenzie de Educação Física e Esporte (B3). É importante ressaltar que algumas revistas tiveram um trato específico. A revista Motriz, a partir de 2013, passou a publicar artigos somente em língua estrangeira, e por esse motivo a pesquisa foi feita até esse marco. A Revista Brasileira de Educação Física e Esporte tem como última edição publicada no ano de 2018, e a Revista Brasileira de Ciências do Esporte tem como o volume de suas edições atuais do ano de 2017, e por esse motivo a catalogação foi feita até esse ano respectivamente. A Revista Mackenzie de Educação Física e Esporte tem seu início de publicação no ano de 2002 e como sua última edição o volume publicado no ano de 2016, e por esse motivo a catalogação foi feita até nesse intervalo de período.

O recorte temporal da presente pesquisa se deu do ano de 2000 até o fim do primeiro semestre de 2019. O primeiro limite tem por base o que Coutinho et al. (2012) pontua, ao afirmar que a produção acadêmica de artigos em periódicos brasileiros sobre a Educação Física escolar obteve um crescimento expressivo a partir do ano de 2000. O segundo marco se refere ao período de finalização da catalogação dos artigos.

A pesquisa se deu por meio do acesso a cada volume de todos os periódicos, no recorte temporal definido. Como critério de inclusão foram selecionados artigos que, com base na leitura do título, resumo, palavras-chave e, em alguns casos o texto na íntegra, apresentavam discussões sobre o aproveitamento do tempo, gerenciamento do tempo ou até mesmo quando a

\footnotetext{
${ }^{4} \mathrm{O}$ Qualis se refere ao sistema de avaliação de periódicos, coordenado de CAPES. Sua função é exclusivamente avaliar a produção científica dos programas de pós-graduação. Esse processo foi criado para atender as necessidades específicas do sistema de avaliação da Coordenação de Aperfeiçoamento de Pessoa de Nível Superior.
} 
palavra "tempo" estava presente, sempre relacionados à conjuntura da aula de Educação Física escolar. Estudos relacionados a motivação, estratégias, didática, planejamento, competência, entre outros, foram selecionados para compor esta pesquisa pelo fato de o "tempo" se tratar de um tema amplo e que é influenciado e influencia esses e outros fatores relacionados às aulas de Educação Física. Foram excluídos artigos em língua estrangeira, que estavam fora do recorte temporal estabelecido e também os que não disponibilizavam o arquivo completo para visualização.

A catalogação do que foi encontrado foi realizada em uma planilha eletrônica ${ }^{5}$ e utilizou-se as seguintes informações contidas nos artigos: a) nome do artigo; b) temática; c) autor (es); d) número de autores por artigo; e) ano de publicação; f) instituição de vínculo dos autores; g) país da instituição; e h) nome da revista. As informações que não foram localizadas nos próprios artigos foram coletadas no Currículo Lattes, condizentes com o ano de publicação do artigo. É importante salientar a vulnerabilidade da catalogação nas informações de alguns autores, visto que algumas informações não estão cadastradas, dificultando sua obtenção. Por esse motivo, as informações não encontradas foram registradas como "N/E" (não encontrado).

Após a catalogação, para identificar os enfoques temáticos dos artigos, realizou-se uma leitura completa dos resumos e também uma leitura preliminar e/ou completa dos trabalhos para, na sequência, organizá-los em categorias que agrupassem os temas encontrados. Para tal, foi utilizada uma técnica baseada em Guerra (2006) na elaboração dessas categorias. A autora permite a criação de grupos temáticos com base na proximidade dos assuntos tratados nos artigos. Assim, os manuscritos foram catalogados e agrupados por similaridade. Posteriormente esses conjuntos de textos foram classificados pelos autores (as) nas seguintes categorias:

- Tempo: condiz com os estudos que abordam o aproveitamento do tempo da aula, gerenciamento dos subtempos ${ }^{6}$, gestão do tempo útil e tempo de aprendizagem ativa das aulas.

- Práticas pedagógicas: estudos que envolvem relatos de estratégias de ensino, metodologias, didáticas, fazeres pedagógicos com relação à indisciplina, tratando do tempo secundariamente.

\footnotetext{
5 A planilha eletrônica onde foi realizada a catalogação se encontra disponível no link a seguir: https://drive.google.com/file/d/11FeDfyYwtEJa1F9CJgJN40ja51LWVwm6/view?usp=sharing.

${ }^{6}$ Subtempos aqui é entendido como o tempo total da aula divido em momentos característicos, como medida de exemplo, Graham, Holt/Hale e Parker (1992) dividem esses momentos em: tempo administrativo, tempo de espera, tempo de prática e tempo de instrução.
} 
- Competência: estudos que envolvem práticas consideradas de um "bom" professor no tempo de aula.

- Motivação: estudos que envolvem períodos de atenção, percepções dos alunos acerca do tempo de aula, fatores que levam à participação em aula, bem como à desmotivação e à não participação.

- Planejamento: estudos que envolvem a questão do tempo no planejamento e na estruturação das aulas, dos conteúdos, bem como os planejamentos estratégicos para esse fim.

A exposição dos resultados da pesquisa é resultante da sistematização na planilha eletrônica e se dá por meio da ferramenta tabela dinâmica, onde os dados são apresentados por meio de representação gráfica. Em primeiro lugar serão apresentados os dados gerais, detalhando a quantidade de publicações cronologicamente e sua distribuição nos periódicos. Em seguida serão evidenciados os autores e as instituições com maior produtividade e, por fim, serão detalhados os artigos classificados em cada um dos eixos temáticos. As análises serão realizadas com base nos referenciais teóricos levantados e também complementares.

\section{RESUltados E DiscuSSÕES}

Com base nos dados levantados, a seguir apresenta-se a distribuição dos $55 \operatorname{artigos}^{7}$ encontrados durante a periodicidade citada anteriormente (2000-2019), conforme a Figura 1 a seguir:

Figura 1 - Quantidades de artigos por ano

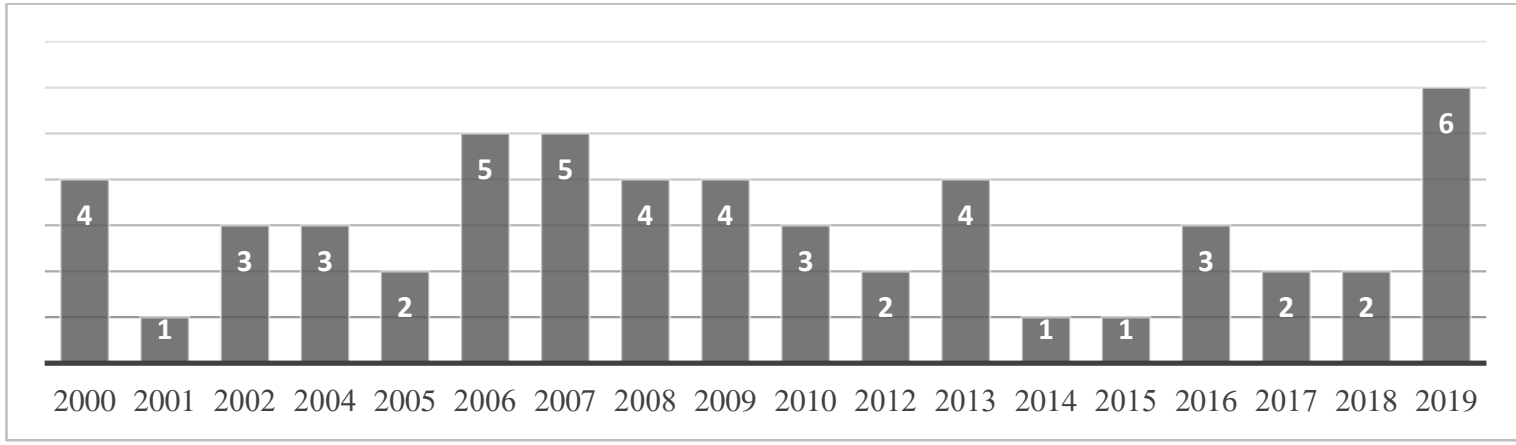

Fonte: Os autores (2019).

Como se pode observar, apesar de o maior número de publicações ser do ano de 2019, o período em que mais teve artigos publicados referente ao assunto pesquisado foi na primeira década, tendo uma redução na quantidade de publicações a partir da segunda década e

\footnotetext{
${ }^{7}$ A relação entre os títulos dos artigos levantados com seus respectivos autores e os eixos temáticos se encontra no link a seguir: https://drive.google.com/file/d/18 cbAZHyofp4Ddcr0ersTdAk4lEcPy2H/view?usp=sharing. 
possivelmente retornando a partir do ano atual. Vale ressaltar que essa baixa produção pode ser explicada pelo fato de que algumas revistas, como especificado anteriormente, atrasaram as publicações de seus volumes, não estando disponibilizados para visualização, além de que outras passaram a publicar somente em língua estrangeira.

Para evidenciar as publicações e a distribuição dessas nos periódicos em questão, a Figura 2 a seguir mostra a quantidade de artigos pulicados por cada revista:

Figura 2 - Revistas com mais publicações

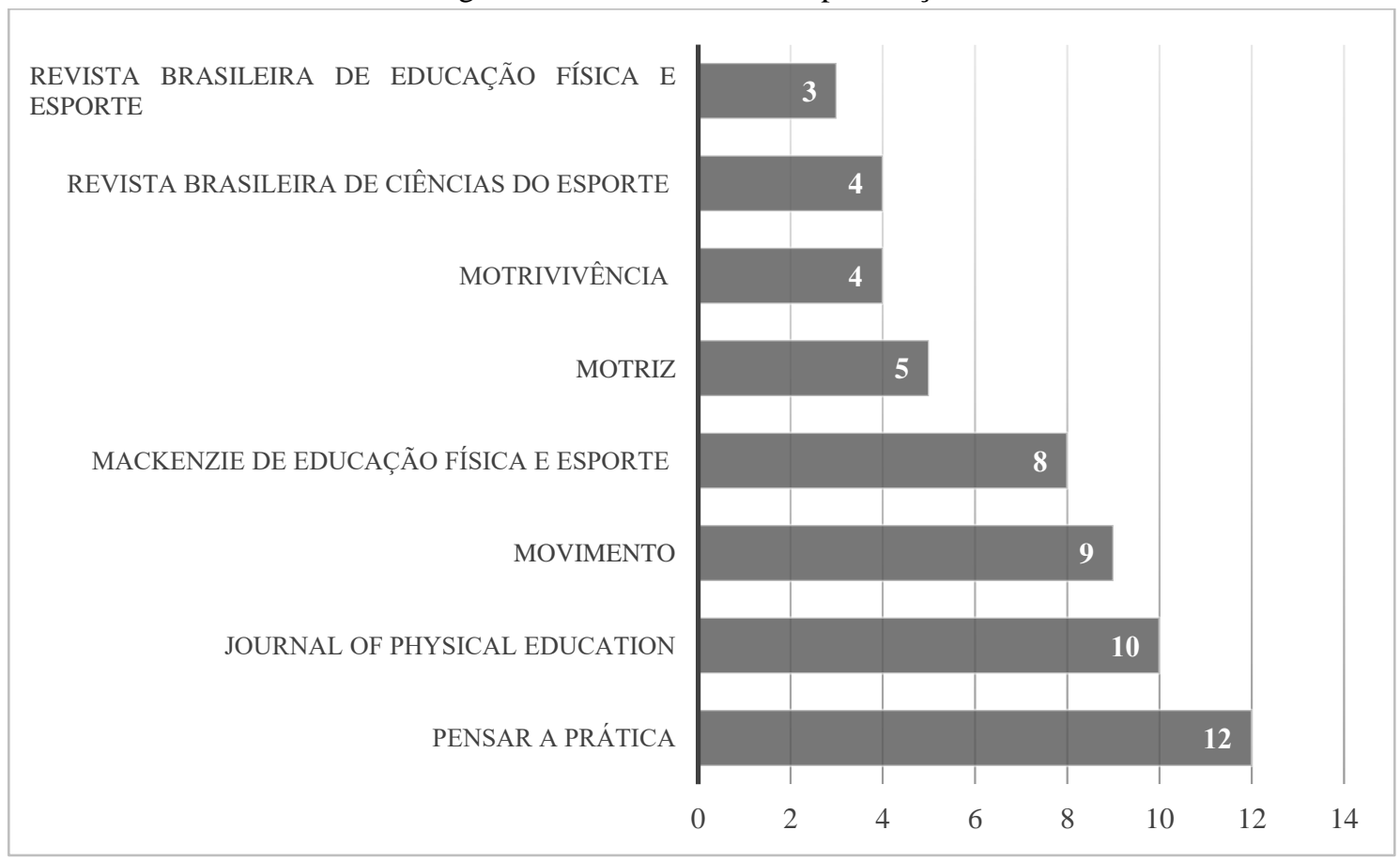

Fonte: Os autores (2019).

A predominância da revista Pensar a Prática pode ser explicada pelo fato de o periódico possuir foco e escopo ligados às ciências humanas e sociais, em seus aspectos pedagógicos, históricos, socioculturais e filosóficos. Essa afinidade da revista com o objeto de pesquisa a leva ao topo na figura. A revista Journal Of Physical Education também possui uma seção que trata de aspectos pedagógicos e culturais. Em $3^{\circ}$ lugar na figura, a revista Movimento também aborda temas bem próximos da revista Pensar a Prática. Vale ressaltar ainda que os autores que mais aparecem quanto ao número de artigos publicados são/já foram vinculados às instituições que administram essas revistas que mais contemplam artigos. Essas três revistas citadas concentram a maior parte das publicações.

Pensando na relação entre as revistas que mais publicam e as aproximações entre autores e instituições, a Figura 3 a seguir mostra as instituições que tiveram mais autores vinculados. 
Figura 3 - 10 instituições com mais autores vinculados

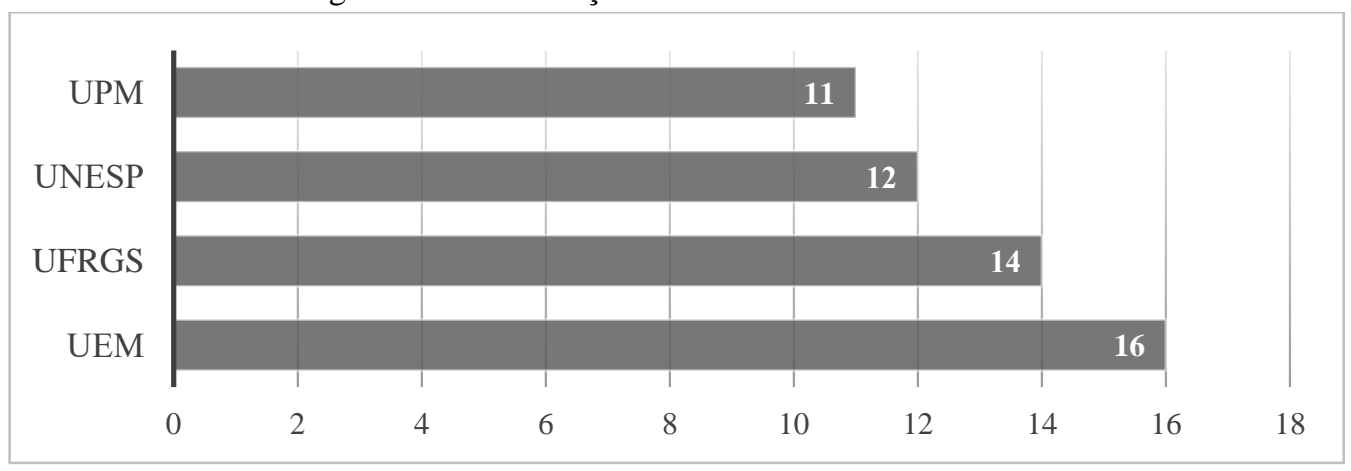

Fonte: Os autores (2019)

A Universidade Estadual de Maringá (UEM) foi a universidade que mais apresentou autores vinculados, somando 16 aparições. A universidade fica localizada na cidade de Maringá, no estado do Paraná, e foi fundada em 1969. Possui uma importante revista para o âmbito da Educação Física que é a Journal Of Physical Education, periódico que consta diversas vezes como um dos que mais divulgam estudos sobre o objeto investigado. O Programa de Pós-Graduação associado em Educação Física da universidade possui, em uma das duas grandes áreas de concentração, linhas de pesquisa relacionadas a práticas sociais em Educação Física, que envolvem temas como: trabalho, formação, práticas escolares, políticas e produção do conhecimento em Educação Física, propiciando, portanto, um cenário adequado para que as pesquisas sobre o contexto escolar sejam elaboradas, sendo compreensível o elevado número apresentado de autores que escreveram sobre as temáticas catalogadas neste estudo.

Com 14 aparições, a Universidade Federal do Rio Grande do Sul, que fica localizada na cidade de Porto Alegre, no Rio Grande do Sul, e foi fundada em 1950. A instituição possui uma importante revista para o âmbito da Educação Física que é a Movimento, revista de maior Qualis utilizada neste estudo. Além disso, o Programa de Pós-Graduação em Ciências do Movimento Humano (PPGCMH) da universidade, em que a Educação Física se enquadra, possui grupos de pesquisas que se relacionam ao objeto de pesquisa, sendo eles: Didática e Metodologia do Ensino da Educação Física (DIMEEF), Grupo de Estudos Qualitativos, Formação de Professores e Prática Pedagógica em Educação Física e Ciências do Esporte (F3PEFICE), Grupo de estudos em Docência e Avaliação em Educação Física (GEDAEF) e Grupo de Estudos Socioculturais em Educação Física (GESEF).

Com 12 aparições, a Universidade Estadual Paulista (UNESP) vem na sequência. Foi fundada em 1976 e possui diversos campi localizados em vários pontos do interior paulista. A universidade possui uma importante revista para a área da Educação Física que é a Motriz, a 
qual também foi um lócus de difusão sobre o tema, mesmo que, atualmente, suas publicações tenham o foco em estudos mais biológicos.

Em seguida, com 11 aparições, a Universidade Presbiteriana Mackenzie (UPM), que fica localizada na capital do estado de São Paulo e foi fundada como universidade em 1952. Possui uma importante revista no âmbito da Educação Física que é a Revista Mackenzie de Educação Física e Esporte, porém a submissão de artigos está suspensa por tempo indeterminado desde 2014, sendo a última publicação em 2016. O programa de pós-graduação associado à área de concentração de Educação, Arte e História da Cultura tem suas linhas mais voltadas a temas como: formação do educador para a interdisciplinaridade, linguagens e tecnologias, e culturas e artes na contemporaneidade.

Com base nos resultados encontrados, entende-se que há uma relação muito próxima entre as instituições encontradas, seus programas de pós-graduação e suas linhas de pesquisa com as temáticas que envolvem este estudo. Muitos dos programas possuem linhas específicas sobre Educação Física escolar ou a Educação Física em uma perspectiva mais social e cultural, demonstrando essa correlação entre oferta e demanda no sentido de que os estudos encontrados são objetos de pesquisa de linhas específicas que tratam desse assunto, não sendo algo vago ou isolado em uma linha não correspondente. Além disso, os resultados comprovam que o que foi encontrado realmente está sendo pesquisado por grupos destinados a essa finalidade.

Os autores, instituições e grupos de pesquisas, ao final, concretizam um dos produtos mais valiosos para a academia: os artigos científicos (DART, 2014). Assim, a fim de identificar a quantidade de publicações em cada eixo anunciado na metodologia, na Figura 4 abaixo estão listados os artigos encontrados nas revistas que versam sobre o tempo nas aulas de Educação Física e suas influências:

Figura 4 - Número de artigos por eixo temático

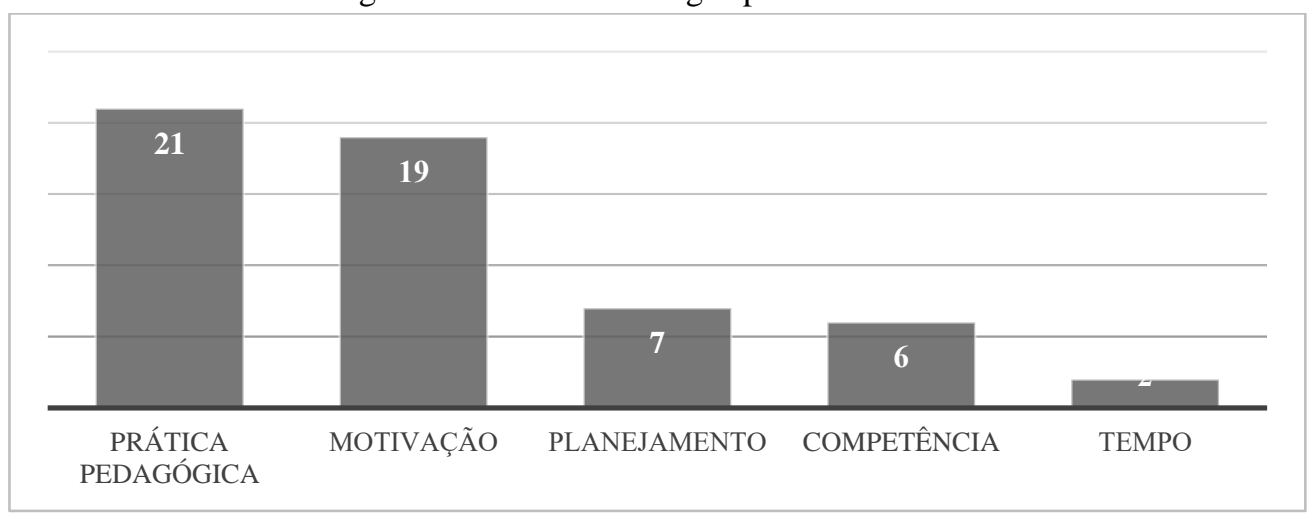

Fonte: Os autores (2019). 
Ao analisar os dados é perceptível a inclinação dos estudos referentes às práticas pedagógicas e às questões motivacionais nas aulas de Educação Física, visto que o tempo é uma das principais variáveis desses fatores. No entanto, é possível observar que o tempo não teve centralidade nos trabalhos encontrados, sendo discutido geralmente de maneira secundária.

O eixo denominado como "Práticas Pedagógicas" aborda estudos relacionados às estratégias de ensino, os fazeres pedagógicos relatados e/ou considerados inovadores pelos autores que publicaram sobre esse tema. Envolve também estudos condizentes às questões metodológicas e didáticas das aulas de Educação Física, bem como atitudes e procedimentos voltados para questões indisciplinares na aula. Os artigos encontrados nesse tema abordam o tempo de modo secundário, buscando entender de que forma essas variáveis que compõem a prática podem influenciar ou influenciam o tempo da aula.

Para elucidar do que se trata esse eixo, traz-se como exemplo o estudo de Costa, Santos e Ferreira (2013). Os autores acompanharam as atividades de uma professora em início de carreira, com o objetivo de descrever o que foi observado a fim de identificar as percepções da professora sobre o começo da atuação profissional. Os autores encontraram junto à professora muitos fatores restritivos com os agentes escolares, como, principalmente, a resistência dos alunos durante a prática pedagógica, a falta de organização escolar e de apoio da direção com a disciplina. Outro fator frisado tem relação à infraestrutura e seu impacto no tempo da aula, a professora diz que "[...] o tempo disponível de aula condiciona a sua atuação porque dificilmente a duração prevista decorre de forma otimizada" (COSTA, SANTOS \& FERREIRA, 2013, p.180).

Os 21 artigos são encontrados nas seguintes revistas: Movimento (SCHERER; MOLINA NETO, 2000; WITTIZORECKI; MOLINA NETO, 2005; ALMEIDA; FENSTERSEIFER, 2007; SOUZA, 2007; SANTOS et al., 2008; REZER, 2015), Journal Of Physical Education (COSTA E NASCIMENTO, 2006; OLIVEIRA; SILVA, 2018; SOUSA; MOURA, 2019), Revista Brasileira de Ciências do Esporte (BRACHT et al., 2002; CAPARRÓZ; BRACHT, 2007), Revista Brasileira de Educação Física e Esporte (BARROS; DARIDO, 2009; SANCHOTENE; MOLINA NETO, 2013), Pensar a Prática (SOUZA, 2001; SANCHOTENE; MOLINA NETO, 2006; SILVA, 2013; SOUZA et al., 2017; CARVALHO; SOUZA NETO, 2019), Revista Mackenzie de Educação Física e Esporte (COSTA; SANTOS; FERREIRA, 2013) e Motrivivência (ARAÚJO, 2012; BELMOUNT; OSBORNE; LEMOS, 2019). 
No eixo denominado como "Motivação" são abordados artigos que tratam questões que envolvem a motivação de professores e alunos, a participação dos alunos nas aulas e os efeitos dessa participação, as percepções que esses alunos têm pelo tempo na aula de Educação Física escolar, além de conteúdos, estrutura e materiais, estudos que tratam da atenção dos alunos nas aulas, mas também isso visto do modo contrário, estudos que tratam de fatores que levam à desmotivação das aulas, bem como a não participação. Aqui se elucida, igualmente, a questão do tempo, mesmo que secundariamente a essa temática, buscando entender de que forma as questões denominadas nesse eixo podem influenciar a questão do tempo de aula.

Os 19 artigos são encontrados nas revistas: Journal Of Physical Education (JUNIOR, 2000; CHICATI, 2000; FOLLE; POZZOPON; BRUM, 2005; PERFEITO et al., 2008; SANTOS et al., 2019), Motriz (MARANTE; FERRAZ, 2006; MINELLI et al., 2010), Revista Brasileira de Ciências do Esporte (PIZANI et al., 2016), Revista Brasileira de Educação Física e Esporte (DARIDO, 2004;), Pensar a Prática (SILVA; JANUÁRIO, 2009; MILLEN NETO et al., 2010; MARTINS; FREIRE, 2013; MOURA SANTOS et al., 2017; VIAN et al., 2019), Revista Mackenzie de Educação Física e Esportes (PAIANO, 2006; MARTINELLI et al., 2006; MENUCHI; NETO, 2014; FILGUEIRAS; GARCIA, 2016) e Motrivivência (BENTO; RIBEIRO, 2008).

No eixo denominado como "Planejamento" são incluídos estudos que tratam sobre a construção do planejamento, bem como a sua importância em todo o processo escolar, a estruturação das aulas, a participação dos alunos nesse planejamento, a seleção dos conteúdos para esse fim e as suas influências no fazer pedagógico. Esses estudos mostram que todo esse processo influencia na construção de uma aula em que o tempo é mais aproveitado.

Para tratar desse eixo podemos citar o estudo feito por Resende, Soares e Moura (2009), em que os autores têm como objetivo caracterizar e analisar os modelos de estruturação das aulas, fazendo isso com base no depoimento de professores atuantes no ensino da Educação Física escolar. Os autores encontram resultados inesperados, centrados na existência de duas perspectivas de planejamento e estruturação das aulas. Uma estruturada em partes compartimentalizadas e outra planejada de maneira integrada, sendo que nas duas formas os professores relatam que estruturam suas aulas de modo que todos façam - e ao mesmo tempo. Também foi identificado um grupo de professores que não tinham clareza sobre a forma de organização de suas aulas. Essa falta de clareza é entendida como uma possível causa da incoerência pedagógica e também na falta de objetivos centrados de uma aula, possibilitando que esse tipo de prática possivelmente não propicie uma boa utilização do tempo, pois esse 
tempo é tratado pelos autores como necessário para se alcançar uma consecução dos objetivos de uma aula, e que deve ser subordinado às experiências pedagógicas e às ações dos alunos.

Os 7 artigos são encontrados nas revistas: Movimento (DOCENTE, 2002; PALAFOX, 2004; TERRA, 2004), Journal Of Physical Education (LOPES et al., 2016), Motriz (RESENDE; SOARES; MOURA, 2009), Revista Mackenzie de Educação Física e Esporte (SOUZA; FREIRE, 2008) e Motrivivência (FARIAS et al., 2019).

A temática "Competências" contempla artigos que dizem respeito principalmente a competências e características ditas de um "bom professor" e de que forma isso influencia ou pode influenciar o tempo de aula, principalmente de que forma o professor se utiliza desse tempo. Encontraram-se estudos com base em pesquisas com professores recém-formados, professores com mais de 20 anos de atuação, professores em formação e também alunos desses professores.

Tratando desse eixo podemos citar resultados de artigos como o de Da Silva et al. (2007) em que os autores concluem que a Educação Física encontra problemas nos seus âmbitos, mas as práticas consideradas de êxito acontecem por meio de ações voltadas para a qualidade do processo educacional, ou seja, o professor que encontra na sua prática processos e atitudes que implicam a qualidade de sua aula tem êxito nela pois soube utilizar-se bem do seu tempo de aula. Os 6 artigos são encontrados nas revistas: Jounal Of Physical Education (DA COSTA; NASCIMENTO, 2009), Motriz (BELTRÃO; MACÁRIO, 2000; CORREIA; FERRAZ, 2010), Revista Brasileira de Ciências do Esporte (DA SILVA et al., 2007), Pensar a Prática (PAIXÃO et al., 2018) e Revista Mackenzie de Educação Física e Esporte (GALVÃO, 2002).

A temática denominada "Tempo" comtempla artigos que abordam como é a administração do tempo de aula, como a distribuição desse tempo vem sendo feita nas aulas de Educação Física escolar, discussões sobre o porquê dessa questão do tempo ser importante para as aulas e o quanto os alunos estão ligados a essa questão. Esses artigos tratam sobre o nível de atividade física de crianças e adolescentes durante o tempo nas aulas de Educação Física escolar, como aumentar o tempo de participação nas aulas, e fazem comparações sobre diferentes aulas para identificar possíveis níveis de aproveitamento, além de indicarem soluções práticas para contribuir com esses feitos. Nessa temática foi percebido um cunho técnico das publicações, dividindo o tempo em subtempos e analisando a distribuição percentual em todos esses tópicos. Os 2 artigos são encontrados nas revistas: Pensar a Prática (DA COSTA; TOIGO, 2012) e Revista Mackenzie de Educação Física e Esporte (TOIGO, 2007). 
Por fim, observa-se que todos os estudos localizados trazem discussões importantes tanto para o cenário acadêmico-científico quanto para aqueles que estão no chão da escola e que, inevitavelmente, deparam-se com problemáticas relacionadas ao tempo, visto que muitos ainda não reconhecem esse fator como uma determinante na qualidade das aulas. Assim, este estudo consegue apontar algumas das pesquisas que se propuseram a discutir esse fator, bem como sinaliza as lacunas que podem e devem ser preenchidas para o fomento de maiores estudos com esse viés, os quais são necessários para um maior desenvolvimento na área.

\section{CONSIDERAÇÕES FINAIS}

O presente estudo teve como objetivo geral identificar as formas pelas quais a produção científica na área da Educação Física tem tratado o tema sobre o tempo e sua influência nas estratégias metodológicas, didáticas e no fazer pedagógico do professor nas aulas de Educação Física escolar. Este estudo é de grande importância à medida que com base nos resultados obtidos será possível identificar como a produção científica trata as questões sobre o tempo e suas influências. Além disso, também identificou quais são esses polos de produção e em quais revistas se encontram.

O tipo de pesquisa realizada se torna importante para encontrar e analisar o recenseamento das produções científicas e acadêmicas existentes em determinadas áreas do conhecimento. Esse tipo de trabalho contribui para uma construção de uma memória da Educação, uma vez que produz um banco de dados sobre as produções por meio do mapeamento e discussão das pesquisas. Torna-se importante identificar o que já tem produzido para posteriormente buscar o que ainda não é tão explorado e contribuir sempre para o desenvolvimento da área.

Encontrou-se 55 artigos relacionados ao tempo e às suas influências (nas questões de prática pedagógica, motivacionais, de competências e planejamento) nas aulas de Educação Física escolar, distribuídos em 8 revistas nacionais pré-estabelecidas. A revista que obteve o maior número de publicações foi a revista Pensar a Prática, com um total de 12. Com relação às instituições de vínculo dos autores que mais apareceram se destacou a Universidade Estadual de Maringá.

O eixo temático denominado como "Práticas Pedagógicas" totalizou 21 dos 55 artigos encontrados, seguido pelo eixo "Motivação", em que foram enquadrados 19 artigos. Esses dois eixos concentram a maior parte das publicações, tendo uma maior incidência de estudos que fazem relação entre o tempo e suas influências. Em contrapartida, os eixos "Planejamento", 
"Competência" e "Tempo" são menos contemplados com estudos que fazem relação entre o tempo e suas influências, sendo uma lacuna passível de investimento científico. É importante ressaltar que com base nos resultados encontrados na pesquisa, o eixo "Tempo", em específico e de modo central, não se configura como um objeto central por parte dos pesquisadores e merece atenção para os estudos futuros, ainda mais no que corresponde a esse eixo inserido no contexto escolar.

Este estudo, por fim, apresenta os tópicos menos explorados nas pesquisas sobre Educação Física escolar em relação ao tempo e suas influências nas aulas, apontando os caminhos que ainda estão escassos e que necessitam de maior investimento do setor científico. Acredita-se também que os resultados aqui obtidos servirão como um material de apoio e pesquisa para os profissionais da área pensarem sobre essas questões com seus alunos e, principalmente, em suas práticas, aprimorando ainda mais o seu fazer pedagógico.

\section{REFERÊNCIAS}

BATISTA, Cleyton; MOURA, Diego Luz. Princípios metodológicos para o ensino da educação física escolar: o início de um consenso. Journal of Physical Education, v. 30, 2019. Disponível em:

http://www.periodicos.uem.br/ojs/index.php/RevEducFis/article/view/41531

BELMONT, Raquel Saraiva; OSBORNE, Renata; DOS SANTOS LEMOS, Evelyse. A sala de aula invertida na Educação Física escolar. Motrivivência, v. 31, n. 59, 2019. Disponível em: https://periodicos.ufsc.br/index.php/motrivivencia/article/view/2175-8042.2019e57708

BELTRÃO, Fernanda Barroso; MACÁRIO, Nilza Magalhães. O bom professor de educação física: visão do estado, visão do aluno. Motriz: Revista de Educação Física-UNESP, São Paulo, v. 6, n. 2, p. 81-87, 2000. Disponível em:

http://www.rc.unesp.br/ib/efisica/motriz/06n2/Beltrao.pdf

BENTO, Lilian Carla Moreira; RIBEIRO, Romes Dias. As aulas de educação física na concepção dos alunos de $5^{\mathrm{a}}$ a $8^{\mathrm{a}}$ series do ensino fundamental da cidade de Indianópolis-MG. Motrivivência, v. 20, n. 31, p. 354-368, 2008. Disponível em: https://periodicos.ufsc.br/index.php/motrivivencia/article/view/2175-8042.2008n31p354

BOSSLE, Fabiano. Planejamento de ensino na educação física-uma contribuição ao coletivo docente. Movimento, v. 8, n. 1, p. 31-39, 2002. Disponível em:

https://seer.ufrgs.br/Movimento/article/view/2635

BRACHT, Valter et al. A prática pedagógica em Educação Física: a mudança a partir da pesquisa-ação. Revista Brasileira de Ciências do Esporte, v. 23, n. 2, 2002. Disponível em: http://www.oldarchive.rbceonline.org.br/index.php/RBCE/article/view/267 
BRACHT, Valter et al. A Educação Física Escolar como tema da produção do conhecimento nos periódicos da área no Brasil (1980-2010): parte I. Movimento, v. 17, n. 2, p. 11-34, 2011.

CAETANO, Angélica; JANUÁRIO, Carlos. Motivação, teoria das metas discentes e competência percebida. Pensar a Prática, v. 12, n. 2, 2009. Disponível em: https://www.revistas.ufg.br/fef/article/view/5891

CAPARROZ, Fernando Eduardo; BRACHT, Valter. O tempo e o lugar de uma didática da educação física. Revista Brasileira de Ciências do Esporte, v. 28, n. 2, p. 21-37, 2007. Disponível em: http://www.revista.cbce.org.br/index.php/RBCE/article/view/53

CHICATI, Karen Cristina. Motivação nas aulas de educação física no ensino médio. Journal of Physical Education, v. 11, n. 1, p. 97-105, 2000. Disponível em: http://www.periodicos.uem.br/ojs/index.php/RevEducFis/article/view/3799

CORREIA, Rodrigo Nuno Peiró; FERRAZ, Osvaldo Luiz. Competências do professor de educação física e formação profissional. Motriz. v.16, n.2, p. 281-291, 2010. Disponível em: http://www.periodicos.rc.biblioteca.unesp.br/index.php/motriz/article/view/19806574.2010v16n2p281

COSTA, Bruno Oliveira; HENRIQUE, José; DA SILVA FERREIRA, Janaína. Percepções pessoais de uma professora de educação física em início de carreira. Revista Mackenzie de Educação Física e Esporte, v. 12, n. 1, 2013. Disponível em: http://editorarevistas.mackenzie.br/index.php/remef/article/view/5094

COUTINHO, Renato Xavier et al. Análise da produção de conhecimento da Educação Física brasileira sobre o cotidiano escolar. Revista Brasileira de Pós-Graduação, v. 9, n. 17, 2012.

DA COSTA, Luciane Cristina Arantes; DO NASCIMENTO, Juarez Vieira. Prática pedagógica de professores de Educação Física: conteúdos e abordagens pedagógicas. Journal of Physical Education, v. 17, n. 2, p. 161-167, 2006. Disponível em: http://www.periodicos.uem.br/ojs/index.php/RevEducFis/article/view/3336

DA COSTA, Luciane Cristina Arantes; DO NASCIMENTO, Juarez Vieira. O "bom" professor de Educação Física: possibilidades para a competência profissional. Journal of Physical Education, v. 20, n. 1, p. 17-24, 2009. Disponível em: http://www.periodicos.uem.br/ojs/index.php/RevEducFis/article/view/3883

DA COSTA, Thaís Aragão; TOIGO, Adriana Marques. Estudo comparativo sobre o aproveitamento do tempo nas aulas de educação física escolar em uma escola da rede pública estadual e em um programa de atividade física extraclasse da rede pública municipal da cidade de Canoas, Brasil. Pensar a Prática, v. 15, n. 4, 2012. Disponível em: https://www.revistas.ufg.br/fef/article/view/15845 
DA SILVA SOUZA, Maristela. Didática da educação física escolar e o processo lógico de apreensão do saber. Movimento, v. 13, n. 3, p. 181-199, 2007. Disponível em: https://seer.ufrgs.br/Movimento/article/view/3578

DA SILVA, Junior Vagner Pereira. Prática pedagógica em educação física nos anos iniciais do ensino fundamental. Pensar a Prática, v. 16, n. 1, 2013. Disponível em: https://www.revistas.ufg.br/fef/article/view/16421

DA SILVA, Rafael Bernardo et al. A educação física escolar em Maringá: experiências de ensino-aprendizagem no cotidiano das aulas. Revista Brasileira de Ciências do Esporte, v. 28, n. 2, 2007. Disponível em:

http://www.revista.cbce.org.br/index.php/RBCE/article/view/56

DARIDO, Suraya Cristina. A educação física na escola e o processo de formação dos não praticantes de atividade física. Revista brasileira de educação física e esporte, v. 18, n. 1, p. 61-80, 2004. Disponível em: https://www.revistas.usp.br/rbefe/article/view/16551

DART, Eli et al. The science dmz: A network design pattern for data-intensive science. Scientific Programming, v. 22, n. 2, p. 173-185, 2014.

DE ALMEIDA, Luciano; FENSTERSEIFER, Paulo Evaldo. Professoras de educação física: duas histórias, um só destino. Movimento, v. 13, n. 2, p. 13-35, 2007. Disponível em: https://seer.ufrgs.br/Movimento/article/view/3542

DE ARAÚJO, Samuel Nascimento. O tempo e o espaço da educação física em escolas da rede municipal de Guarani das Missões/RS. Motrivivência, n. 39, p. 25-34, 2012. Disponível em: https://periodicos.ufsc.br/index.php/motrivivencia/article/view/2175-8042.2012v24n39p25

DE BARROS, André Minuzzo; DARIDO, Suraya Cristina. Práticas pedagógicas de dois professores mestres em educação física escolar e o tratamento da dimensão conceitual dos conteúdos. Revista Brasileira de Educação Física e Esporte, v. 23, n. 1, p. 61-75, 2009. Disponível em: https://www.revistas.usp.br/rbefe/article/view/16711

DE CARVALHO, Taynara Franco; DE SOUZA NETO, Samuel. A análise de práticas no campo da Educação Física escolar. Pensar a Prática, v. 22, 2019. Disponível em: https://www.revistas.ufg.br/fef/article/view/52978

DE OLIVEIRA, Andreia Camila; DOS SANTOS SILVA, Sheilla Aparecida Pereira. Intervenções pedagógicas do professor em relação a conflitos percebidos entre os alunos durante as aulas de Educação Física. Journal of Physical Education, v. 29, n. 1, 2018. Disponível em: http://www.periodicos.uem.br/ojs/index.php/RevEducFis/article/view/40245 
DE RESENDE, Helder Guerra; SOARES, Antonio Jorge Gonçalves; MOURA, Diego Luz. Caracterização dos modelos de estruturação das aulas de educação física. Motriz - UNESP, v.15, n.1, p. 37-49, 2009. Disponível em:

http://www.periodicos.rc.biblioteca.unesp.br/index.php/motriz/article/view/2003

DE SIQUEIRA FARIAS, Uirá et al. Educação Física escolar no ensino fundamental: o planejamento participativo na organização didático-pedagógica. Motrivivência, v. 31, n. 58, 2019. Disponível em: https://periodicos.ufsc.br/index.php/motrivivencia/article/view/2175$\underline{8042.2019 \mathrm{e} 55270}$

DE SOUZA, Aécio Gomes; DOS SANTOS FREIRE, Elisabete. Planejamento participativo e Educação Física: envolvimento e opinião dos alunos do Ensino Médio. Revista Mackenzie de Educação Física e Esporte, v. 7, n. 3, 2008. Disponível em:

http://editorarevistas.mackenzie.br/index.php/remef/article/view/1486

DE SOUZA CAVALCANTI, Rosiris Pereira. Apropriação e produção de conhecimentos na prática de ensino do professor de Educação Física: um relato de experiência. Pensar a Prática, v. 4, p. 123-134, 2001. Disponível em: https://www.revistas.ufg.br/fef/article/view/81

DOS SANTOS, Josivana Pontes et al. Fatores associados a não participação nas aulas de educação física escolar em adolescentes. Journal of Physical Education, v. 30, 2019. Disponível em: http://www.periodicos.uem.br/ojs/index.php/RevEducFis/article/view/42064

FERREIRA, Norma Sandra de Almeira. As pesquisas denominadas "Estado da Arte". Educação e Sociedade, Campinas, ano XVIII, no. 79, p. 257-272, agosto 2002.

FILGUEIRAS, Isabel Porto; GARCIA, Karine Amado. Empenho do adulto e envolvimento da criança: indícios de aprendizagem significativa em aulas de educação física? Revista Mackenzie de Educação Física e Esporte, v. 15, n. 2, 2016. Disponível em: http://editorarevistas.mackenzie.br/index.php/remef/article/view/11468

FOLLE, Alexandra; POZZOBON, Maria Elizete; BRUM, Carina Fátima. Modelos de ensino, nível de satisfação e fatores motivacionais presentes nas aulas de Educação Física. Journal of Physical Education, v. 16, n. 2, 2005. Disponível em: http://www.periodicos.uem.br/ojs/index.php/RevEducFis/article/view/3386

FORQUIN, Jean Claude. Escola e cultura: as bases sociais e epistemológicas do conhecimento escolar: Porto Alegre: Artes Médicas, 1993.

GALVÃO, Zenaide. Educação física escolar: a prática do bom professor. Revista mackenzie de educação física e esporte, v. 1, n. 1, 2002. Disponível em: http://editorarevistas.mackenzie.br/index.php/remef/article/view/1350 
GUERRA, Isabel Cristina. Pesquisa qualitativa e análise de conteúdo. Sentido e formas de uso, Estoril, Principia Editora, 2006.

GRAHAM, George; HOLT, Shirley Ann; PARKER, Melissa. Children moving: a reflective approach to teaching physical education. Mountain View, Ca: Mayfield, 1992.

JUNIOR, Joaquim Martins. O professor de educação física e a educação física escolar: como motivar o aluno? Journal of physical education, v. 11, n. 1, p. 107-117, 2000. Disponível em: http://www.periodicos.uem.br/ojs/index.php/RevEducFis/article/view/3805

LOPES, Marcia Regina Sousa et al. A prática do planejamento educacional em professores de educação física: construindo uma cultura do planejamento. Journal of Physical Education, v. 27, n. 1, 2016. Disponível em:

http://www.periodicos.uem.br/ojs/index.php/RevEducFis/article/view/30193

MALCOLM, Dominic. Sport and sociology. Routledge, 2012.

MARANTE, Wallace Oliveira; FERRAZ, Osvaldo Luiz. Clima motivacional e educação física escolar: relações e implicações pedagógicas. Motriz - UNESP, v.12, n.6, p. 201-216, 2006. Disponível em:

http://www.periodicos.rc.biblioteca.unesp.br/index.php/motriz/article/view/139

MARTINS, Ana Beatriz Rizzotti; DOS SANTOS FREIRE, Elisabete. O envolvimento dos alunos nas aulas de educação física: um estudo de caso. Pensar a prática, v. 16, n. 3, 2013. Disponível em: https://www.revistas.ufg.br/fef/article/view/19222

MENUCHI, Marcos Rodrigo Trindade Pinheiro; NETO, Benjamin Faro Buente. A relação entre os alunos com dificuldades de coordenação motora e a participação nas aulas de educação física em uma escola de Ilhéus (BA). Revista Mackenzie de Educação Física e Esporte, v. 13, n. 2, 2014. Disponível em:

http://editorarevistas.mackenzie.br/index.php/remef/article/view/4208

MERIDA, Marcos. et al. Educação física no ensino médio: motivos que levam as alunas a não gostarem de participar das aulas. Revista Mackenzie de Educação Física e Esporte, v. 5, n. 2, 2006. Disponível em:

http://editorarevistas.mackenzie.br/index.php/remef/article/view/1288

MINELLI, Daniela Schwabe et al. O estilo motivacional de professores de Educação Física. Motriz: Revista de Educação Física, v. 16, n. 3, p. 598-609, 2010. Disponível em: http://www.periodicos.rc.biblioteca.unesp.br/index.php/motriz/article/view/1980$\underline{6574.2010 \mathrm{v} 16 \mathrm{n} 3 \mathrm{p} 598}$ 
MOROSINI, Marília Costa; FERNANDES, Cleoni Maria Barboza. Estado do Conhecimento: conceitos, finalidades e interlocuções. Educação por escrito, v. 5, n. 2, p. 154-164, 2014.

NETO, Alvaro Rego Millen et al. Evasão escolar e o desinteresse dos alunos nas aulas de Educação Física. Pensar a Prática, v. 13, n. 2, 2010. Disponível em:

https://www.revistas.ufg.br/fef/article/view/7559

PAIANO, Ronê. Possibilidades de orientação da prática pedagógica do professor de educação física: situações de desprazer na opinião dos alunos. Revista Mackenzie de Educação Física e Esporte, v. 5, n. 1, 2006. Disponível em:

http://editorarevistas.mackenzie.br/index.php/remef/article/view/1301

PAIXÃO, Jairo Antônio et al. A prática do bom professor na formação inicial: uma análise na perspectiva de acadêmicos do curso de licenciatura em educação física. Pensar a Prática, v. 21, n. 4, 2018. Disponível em: https://www.revistas.ufg.br/fef/article/view/49712

PALAFOX, Gabriel Humberto Munoz. Planejamento coletivo do trabalho pedagógico da Educação Física-PCTP/EF como sistemática de formação continuada de professores: a experiência de Uberlândia. Movimento (ESEFID/UFRGS), v. 10, n. 1, p. 113-131, 2004. Disponível em: https://seer.ufrgs.br/Movimento/article/view/2828

PERFEITO, Roger Barreto. et al. Avaliação das aulas de Educação Física na percepção dos alunos de escolas públicas e particulares. Journal of Physical Education, v. 19, n. 4, p. 489499, 2008. Disponível em:

http://www.periodicos.uem.br/ojs/index.php/RevEducFis/article/view/6009

PIZANI, Juliana et al. (Des) motivação na educação física escolar: uma análise a partir da teoria da autodeterminação. Revista brasileira de ciências do esporte, v. 38, n. 3, p. 259266, 2016. Disponível em:

http://www.oldarchive.rbceonline.org.br/index.php/RBCE/article/view/1770

QUEIROZ, Daniel Rocha et al. Efeito da participação em aulas de educação física escolar sobre indicadores de crescimento, composição corporal e aptidão neuromotora em crianças. Pensar a Prática, v. 20, n. 4, 2017. Disponível em: https://www.revistas.ufg.br/fef/article/view/43588

REZER, Ricardo. Conhecimento, prática pedagógica e educação física: aproximações com o campo da didática. Movimento (ESEFID/UFRGS), v. 21, n. 3, p. 803-814, 2015. Disponível em: https://seer.ufrgs.br/Movimento/article/view/50983

SANCHOTENE, Mônica Urroz; MOLINA NETO, Vicente. Habitus profissional, currículo oculto e cultura docente: perspectivas para a análise da prática pedagógica dos professores de educação física. Pensar a prática. Goiânia. Vol. 9, n. 2 (jul. dez. 2006), p. 267-280, 2006. Disponível em: https://www.revistas.ufg.br/fef/article/view/173 
SANCHOTENE, Mônica Urroz; MOLINA NETO, Vicente. Rotinas, estratégias e saberes de professores de Educação Física um estudo de caso etnográfico. Revista Brasileira de Educação Física e Esporte, v. 27, n. 3, p. 447-458, 2013. Disponível em: https://www.revistas.usp.br/rbefe/article/view/63115

SANTOS, Ivan Luis. et al. As percepções e os significados para os estagiários de Educação Física em relação à indisciplina na escola. Movimento (ESEFID/UFRGS), v. 14, n. 3, p. 117-137, 2008. Disponível em: https://seer.ufrgs.br/Movimento/article/view/2976

SCHERER, Alexandre; MOLINA NETO, Vicente. O conhecimento pedagógico do professor de Educação Física da escola pública no Rio Grande do Sul-uma etnografia em Porto Alegre. Movimento, v. 7, n. 13, p. 71-80, 2000. Disponível em: https://seer.ufrgs.br/Movimento/article/view/11786

SOUZA, Vânia de Fátima Matias et al. Da ação pedagógica à mudança da prática docente: os jogos e as brincadeiras em uma experiência com o Ensino Médio. Pensar a Prática, v. 20, n. 1, 2017. Disponível em: https://www.revistas.ufg.br/fef/article/view/41125

TERRA, Dinah Vasconcellos. Orientação do trabalho colaborativo na construção do saber docente: a perspectiva do planejamento coletivo do trabalho pedagógico (PCTP). Movimento (ESEFID/UFRGS), v. 10, n. 1, p. 157-179, 2004. Disponível em: https://seer.ufrgs.br/Movimento/article/view/2831

TOIGO, Adriana Marques. Níveis de atividade física na educação física escolar e durante o tempo livre em crianças e adolescentes. Revista Mackenzie de Educação Física e Esporte, v. 6, n. 1, 2007. Disponível em:

http://editorarevistas.mackenzie.br/index.php/remef/article/view/1282

VIAN, Fernando et al. Nível de intensidade nas aulas de educação física do ensino fundamental. Pensar a Prática, v. 22, 2019. Disponível em:

https://www.revistas.ufg.br/fef/article/view/50582

WITTIZORECKI, Elisandro Schultz; MOLINA NETO, Vicente. O trabalho docente dos professores de Educação Física na Rede Municipal de Ensino de Porto Alegre. Movimento (ESEFID/UFRGS), v. 11, n. 1, p. 47-70, 2005. Disponível em:

https://seer.ufrgs.br/Movimento/article/view/2861

Recebido em: 27 de julho de 2020.

Aprovado em: 20 de dezembro de 2021. 